is made by the anterior muscles of the leg. But the symptom is only rarely to be elicited, and is even when present far from being well pronounced; and I think that altogether it does not constitute a strong piece of evidence as to the nature of the case.

Then, against the hysterical hypothesis, there are the very important facts that the patient has remained with one symptom only for three years and a-half, that it took origin during typhoid, and that there never has been the slightest trace of other hysterical symptom, or, indeed, of any nervous symptom in any part of his body except the attacks of insanity, and that these attacks did not in any way modify the motor phenomena which we are studying.

2. Is it Non-hysterical Functional ?-As an example of such a malady, I quote the case of a patient whom I saw frequently, a boy, aged 15 , of a nervous and rheumatic constitution, who had suffered a good deal from Asthma as well as Pneumonia and Acute Rheumatism. After one of his rheumatic attacks he was taken with rather severe chorea, and as the chorea passed off it was noticed that he held his head in a peculiar position, twisted and partly to one side. It was feared by the surgeons in attendance that there might be disease of one of the upper cervical vertebræ. But there was no definite evidence of this. He was carefully treated by constant extension with weight and pulley, but the muscle, on the whole, held its own and resumed the abnormal attitude as soon as set free. The boy never showed a trace of hysterical tendency. At last it was suggested by Professor Ferrier after the condition had persisted many months, that profound narcosis with chloroform should be induced. As soon as he was fairly under, the spasm relaxed, and the boy on awaking was free from it, and never had the slightest recurrence. That is a typical instance of a non-hysterical, but still functional, disease. If our patient's case is functional I should refer it to this class. But its behaviour under chloroform and other modes of treatment is very different from that seen in the case of the boy just quoted.

\section{c. Tox ania.}

It might be suggested that the symptoms are caused by some toxic material acting upon the brain. This suggestion seems to me to have practically nothing in its favour. It is impossible to conceive that a poison should be generated continuously for three and a-half years, that a poison should induce spasm in one-half of the body and in one-half only. The mens medica seems to revolt against such a hypothesis.

$$
\text { D. Organic. }
$$

It may be best to review the series of possible organic changes.

I. Congestion.-It might be a result of congestion ; but a limited congestion of such a kind persisting through so long a period does not correspond to the known facts of medicine.

2. Inflammation.-The same argument holds good, with the addition that spasm persisting, as this has done, is not the kind of result that flows therefrom.

3. Softening, whether due to a pre-existing inflammation, or to a thrombotic or embolic process, could not remain stationary and active through so long a time, even if it could be supposed that mere softening would induce such symptoms.

4. Sclerosis.-If there be organic disfase this seems to me the most probable. It is quite conceivable that during the typhoid a degree of thrombosis occurred, and that sclerosis followed in the affected area. Such a change would be necessarily permanent, and might be arrested and remain limited. I fail to discover anything justifying the absolute exclusion of this suggestion, although it could not apply to a lesion of the cortex, and could not be more than suggested as a possible lesion of the Optic Thalamus.

5. Tumour.-There can be little reason for suggesting a lesion of this kind in the case; for there are neither eye changes, headache, or other symptoms pointing to a lesion of the kind, and a tumour remaining practically stationary for three and a. half years, producing the same symptoms all the time, is not to be conceived.

Conclusion.- On the whole, then, without in the least desiring to dogmatise on the matter, and sitting quite loose to the hypothesis, I would suggest as the most probable diagnosis either sclerosis following upon thrombosis affecting the right optic thalamus, or a non-hysterical functional condition of the whole right psycho-motor cortex, or of the grey matter of the right Optic Thalamus.

Treatment.

Meanwhile, whatever the true pathology of the case may be, we must do what we can in the way of treatment.

It may be well, although there is no history of syphilis, to give potassium iodide a thorough trial, knowing, as we do, that it sometimes proves of unexpected value in obscure cases.

I cannot but hope that as we possess in chloroform a remedy capable of controlling spasm, while at the same time widely affecting the nervous system, we may one day discover a drug or drugs which shall be able to influence spasm without involving the nervous system in other important particulars. Unfortunately we are not yet acquainted with any remedy of such a kind, but I purpose to try any medicines which promise an approach to a fulfilment of the indication.

Lastly, although I very rarely have recourse to treatment by hypnotic suggestion, I have considered myself justified in trying it in this case. My friend Dr. George Kerr has undertaken to apply the method. I am not able as yet to speak definitely of its results. They certainly are not as marked as they generally are in purely functional cases.

\section{CLINICAL MICROSCOPY AT JOHNS HOPKINS MEDICAL SCHOOL, BALTIMORE, UNITED STATES OF AMERICA.}

By WILLIAM OSLER, M.D., F.R.S.,

Professor of Medicine, Johns Hopkins University.

THREe years ago, in the second year of the organisation of the medical school, the clinical laboratory was built, in part by a bequest of $\$ 10,000$ from friends interested in medical education. It consists of two storeys, each of which has a main laboratory floor 64 feet by 20 feet, with windows on either side, and accommodation in each for 60 students. There are six smaller rooms for the assistants and for private work. One laboratory is exclusively for the third-year, the other for the fourth-year, students. Before proceeding to speak of the classes, I may refer to the organisation of the medical service of the hospital. There are four more or less permanent officers : a first assistant or resident physician, with two juniors, one of whom takes charge of the private ward, the other of the bacteriology of the service; and a physician in charge of the clinical laboratory. The permanency of these officers is of the greatest advantage ts the service. Since the opening of the hospital nine years ago I have had only two first assistants, Dr. Lafleur, now of MeGill University, Montreal, and Dr. Thayer, who has been with us seven years. The first assistant gets his quarters and $\$ 500$ a year from the hospital, and $\$ 500$ from the medical school for helping with the teaching. He is also allowed the privilege of outside consultation work. These are appointed by the trustees on the nomination of the Medical Board. There are four house-physicians selected each year from the graduating class. The general microscopical and chemical work of the wards is done in three separate rooms under Ward $G$, the equipment and current expenses of which are paid for by the hospital. The expenses of the clinical laboratory are met by the medical school.

The work of the third year in medicine consists of (1) an out-patient class from 12 to 1 three times weekly. Adjoining the medical dispensary is a class room accommodating 50 students. I take charge of this class, in which are considered the objective features of disease as illustrated in select cases. (2) On Wednesday, at 12, I hold a set clinic in the amphitheatre, at which both third and fourth-year students attend. (3) Twice a week for two hours Dr. Thayer takes the class in physical diagnosis. (4) On Monday and Friday, from 2 to 4.30 P.M., Dr. Futcher meets the class in clinical microscopy. It may be well to state here that our classes are as yet small, and as the students enter the school with laboratory training in both biology and chemistry, they are able to take pathology and bacteriology in the second year, so that they have an excellent preparation for the clinical microscopy.

The microscopes and reagents are provided, each student paying a rental of $\$ 5$ a year for the microscope. 
Synopsis of Course on Clinical Microscopy.

The course begins on October ist, and continues throughout the academic year (to June ist). Two laboratory classes of two and a half hours duration are held weekly. In addition, a one hour's recitation on the work already taken up is held each week. The course includes a thorough study of the blood, urine, sputum, gastric juice, and fæces, and other specimens of importance occurring in the wards from time to time.

\section{A. THE BLOOD.}

I. Consideration of the various views held concerning the origin of the red blood cells and leucocytes during intrauterine and extrauterine life

II. Examination of fresh specimens of normal blood : (a) Study of the normal red cell, and the changes it may undergo owing to improper normanipulation; $(b)$ study of the various types of leucocytes in a fresh specimen of normal blood; (c) study of blood platelets in normal and diseased blood.

III. Methods of counting the red and white corpuscles, with the ThomaZeiss blood counters, including the use of the hematocrit

IV. Methods of determining the hxemoglobin : (a) Von Fleischl's ; $(b)$ Gowers's.

v. Demonstration of methods of determining the speeific gravity of

tube

ves wrich's method of blod ommination by study of dred (a) Fixing of specimens: (I) By heat on a copper or in thermens ; (2) by alcolol and etler in show the various elements of the blood which have an affinity for acid, basic, or neutral dyes: (I) Specimons stained with eosin ; (2) methylene riple stain ( (6) show perinuclear basophilic granule

tIII. Examination of blood for malarial parasites: (a) Fresh blood, to show the various stages of development of ' the teitian resh blood, to estivo-autumnal parasites; (b) permanent specimens stained in eosin and methylene blue to show the same.

IX. Demonstration of filaria sanguinis hominis in $f: e s h$ blood.

$x$. Study of the leucocytes, with permanent specimens:(a) physiological; (b) pathological.

XI. Study of the bone marrow, spleen, and lymphatic gland, with especial reference to the origin of the red and white corpuscles, and to the

regeneration taking place after liæmorrhages and in grave anæmia.
xII.Study of the various varieties of anæmia, with permanent specimens : (a) Primary anæmia: (I) chloros s ; (2) progressive pernicious anæmia; 3) leukæmia, (a) spleno-myelogenous, $(\beta$, lymphatic ; ( $)$ pseudo-
leukæmia. (b) Secondary anæmia : (x) following hæmorrhage, (2) following malignant diseases, (3) following malarial infections

xni. Consideration of the blood changes in : (a) Various infectious diseases-diphtheria, measles, scarlet fever, trphoid. tuberculosis, etc.: $(b)$ syphilis ; (c) nephritis; $(d)$ diseases of the heart; $(c)$ pneumonia;

\section{B. THE URINE.}

1. Theories of the excretion and secretion of urine.

II. Physical examination of the urine. Full consideration of ' the features to be noted under this heading.

III. Chemical examination of the urine: (a) Organic constituents : (x) Tests for the various proteids and proteoses in the urine, including (a) albumin, with methods for quantitative determination, (B) peptone. ( $\gamma$ ) fibrin,

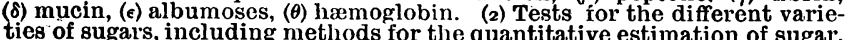
ties of sugars, including methods for the quantitative estimation of sugar. (3) Organic substances which may reduce copper solutions and simulate glycosuria, as homogentisinic acid (alkaptonuria) and glycuronic acid. (4) Tests for acetone, diacetic acid, and $\beta$-oxy-butyric acid. (5) Colouring
matters : normal: (a) urobilin, $(\beta)$ urine indican ; abnormal: $(\alpha)$ colouring matters : normal : ( $(\alpha)$ urobilin, $(\beta)$ urine indican; ; abnormal : ( $(\alpha)$ colouring matters of the blood. ( $\beta$ ) pile pigments, $(\gamma)$ vegetable colouring matters. (6) Leucin and thyrosin and xanthin. (7) Urea, qualitative and quantitative determination of. (8) Uric acid. (9) Method of estimating total nitrogen in the urine by the Kjeldalli process. (ro) Krüger and Wullf's method of estimating the alloxuric bodies in the urine. (b) Inorganic
comstituents: (x) Chlorides, quantitative and qualitative determination of. (2) Phosphates: (a) earthy, qualitative and approximate quantitative determination of; $(\beta$, alkaline : quantitative estimation of total phosphoric acid. (3) Sulphates, qualitative and approxímate quantitative determina-

Iv. Miscellaneous tests : (a) For`Ehrlich's diazo-reaction.

v. Consideration of the toxicity of the urine.

VI. Microscopical examination of urinary sediment: (a) Unorganised deposits, including crystalline and amorphous deposits; various microchemical tests for purposes of differentiation. (b) Organised deposits, including anatomical elements as epithelial, red blood and pus cells.
false and true tube casts, etc. c) Staining for tubercle bacilli ; methods recommended for differentiation from smegma bacilli. (d) staining for gonococci.

C. The Sputum

I. General considerations regarding collection of and prevention from contamination. Information obtained from a macroscopical examination of the
II. sputum

III. Microscopical examination of buccal secretion.

1v. Microscopical examination of sputum. Examination for (a) red blood and pus cells, including eosinophilic cells. (b) Epithelial cells. degeneration of the and alveolar' epithelial cells. Study of the myelin degeneration of the latter, and of the various varieties of pigment they tissue - methods of examining for it types of "dust cells." (c) Elastic rinous casts of bronchi. ( $f$, Various types of crostals; Charcot-Leyden, hæmatoidin. fatty, etc. ( $g$ ) Examination for amoeba col

v. Methods of staining for various pathogenic bacteria, tubercle bacilli, pneumococci, etc. vi. The sputum in the following diseases was studied macroscopically and microscopically : (a) bronchitis, various types; $(b)$ pneumonia, lobar and acute tuberculous pneumonia; (c) pulmonary tuberculosis, various stages; d) asthma; (e) bronchiectasis; $(f$, hepatic abscess opening into
bronchus, with examination for amœbæ coli, etc.; $(g)$ pneumonokoniosis.

\section{Gastric Juice.}

I. General consideration : of the anatomy of the stomach and the physiology. of gastric digestion.

II. Consideration of the normal constituents of the gastric juice.

III. Various forms of test breakfasts.

Iv. Method of removing the gastric contents with a practical demonstration. Amount and appearance of contents in healthy digestion. v. Chemical examination of gastric contents : (a) Reaction to litmus (b) Tests for free acids; (c) Tests for free hydrochloric acid; $(d)$ Tests fo lactic acid: $:(e)$ Tests for butylic and acetic acids ; $(f)$ Quantitative estima-
tion of total acidity; $(g)$ Estimation of free hydrocloric acid ; $(h)$ Tests for tion of total acidity; $(g)$ Estimation of free hydrocloric acid; $(h)$ Tests

pepsin, pepsinogen, and rennet; $(i)$ Test for starch and its derivatives. (b) For blood, or portions of mucous membrane and malignant growths; (c) For sarcinæ and other vegetable growths.

vir. Method of determining the absorptive and imotor power of the stomach.

vill. Changes in the gastric juice occurring in various systemic and local diseases of the stomach: (a) Chlorosis; (b) Neurasthenia; (c) Gastritis, stomach; $(f)$ Ulcer of the atomach; $(g)$ Dilatation of the stomach.

\section{E. THF FECES}

I. Macroscopical examination. Effects of medicinal agents on the colour, etc.

II. Microscopical examination: (a) Food débris: (b) Red blood and pus cells ; (c) Intestine epithelial cells ; $(d)$ Amobæ coli ; $(e)$ Differentiation of coli and monads; $(f)$ Examination of fæces for tubercle bacilli; $(g)$ Various forms of crystals

forms of crystals.
IIItestinal parasites. These were fully dealt with by Dr. Stiles in III. Intestinal parasites. These were fully dealt with by Dr. Stiles in
his lectures on animal parasites, when a large number of parasites were
demonstrated. Dr. Stiles also gave four laboratory demonstrations. Trichinæ in the muscles, adult male and femalæ trichinæ in the rat's Trichinæ in the muscles, adult male and femalæ trichinæ in the rat's permanently-stained specimens . of tæniæ illustrating the solium and saginata types.

IV. The special features of the stools in various diseases are dealt with.

Specimens of interest from ward icases not coming.under the above headings are demonstrated to the class from time to time.

Fourth Year Work in Clinical Microscopy.

A place in the laboratory is set apart for each fourth-year student. No systematic instruction is given, but the clinical clerks and surgical dressers make here the special examinations, cut sections (under Dr. Futcher's direction), and use the laboratory for general purposes. Some of them are able to carry out research work. The studies of MacCallum and Opie on the hæmatozoa of birds, MacCallum's studies on the flagellate forms of the malarial organism, T. B. Brown's work on Trichinosis illustrate the character of the work which the senior students can do.

\section{REMARKS ON TWO CASES OF GANGRENE OF THE LUNG.}

BY BYROM BRAMWELL, M.D., F.R.C.P.EDIN., F.R.S.EDIN.,

Physician to the Royal Infirmary, Edinburgh ; Lecturer on the Principles and Practice of Medicine and on Clinical Medicine in the School of Medicine, Edinburgh, etc.

With a Surgical Report on ONe of the Cases BY J. M. COTTERILL, F.R.C.S.EDIN.,

Surgeon to the Edinburgh Royal Infirmary, and Lecturer on Clinical Surgery in the School of Medicine, Edinburgh.

CASE 1.-Gangrenous Inflammation of the Lung, apparently due to the Rupture of an Ulcer of the Stomach into the Lung. Immediate Improvement under: Rectal Feeding; Recovery.-At first sight it was very difficult to explain the clinical phenomena which this case presented, but I am disposed to think that the gangrenous condition of the lung which seemed to be present was the result of the perforation into the thoracic cavity of an ulcer in the upper wall of the stomach, the production of a localised cavity containing fotid contents in connection with the ulcer, and the sudden rupture of the contents of this cavity into the lung tissue or bronchial tubes. This theory is strongly supported by the remarkable improvement which took place immediately rectal feeding was commenced. The notes of the case are as follows: 